\title{
John W. Griffin (1942-2011)
}

One of the world's leading neurologists, Jack Griffin, died on April 16, 2011. John Griffin, known to all as Jack, grew up in Nebraska but received an MD from Stanford University and subsequently trained at the Johns Hopkins Hospital in Neurology followed by two years of postodoctoral training at the National Institutes of Health. The rest of his academic career was spent at Hopkins but his influence went far beyond. Indeed, Jack and his wife, Diane Griffin, also a world authority in neurological infectious and immune diseases, were regarded as models of academic leadership, integrity and success.

Jack Griffin was the quintessential clinician-scientist. He was first and foremost a fine physician who cared for his patients deeply. But he used clinical experiences to fuel his research into the causes of their afflictions and disabilities, especially in the peripheral nervous system. Jack's research spanned fundamental concepts in neuroscience through to the translational stages and into the clinical realm.

Jack's greatest impact was on our understanding of the biology of axons within peripheral nerves

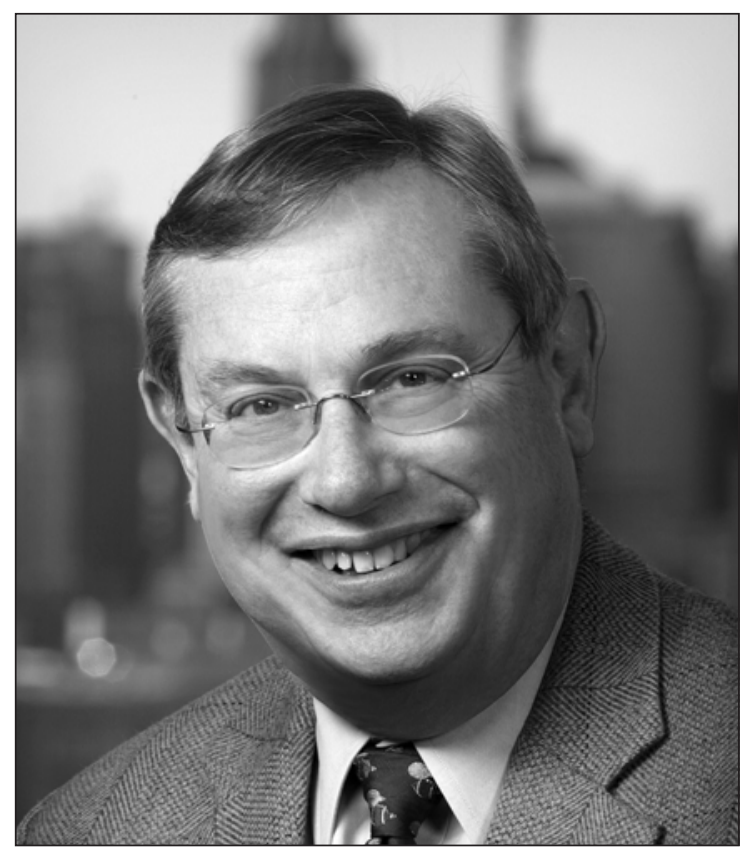
and their relationship to myelin, what damaged them, how they recovered and what might protect them. Clinically, he made substantial contributions to the current concepts underlying the pathogenesis of Guillain-Barre Syndrome (GBS), a paralytic disease affecting peripheral nerves. He was instrumental in launching the major North American clinical trial, which demonstrated plasmapheresis was an effective treatment, and the first, for GBS. He later led a team of researchers to study a unique variant of GBS is northern China that afflicted mainly children. This syndrome proved to be an axonal variant of classical GBS that Jack and his colleagues named Acute Motor Axonal Neuropathy (AMAN). They went on to dissect the pathophysiology of this disease and its relationship to Campylobacter jejuni and show that molecular mimicry was a critical element in its cause. Jack's appetite for research and clinical care were unparalleled-he could often be found in the evening seeing patients or supervising trainees; both Jack and Diane were inevitably present on Saturdays in the office or lab, always making themselves available for questions or just a chat about science or medicine.
Jack was a gifted teacher, a magnanimous leader and a warm and supportive colleague. His talks were models of weaving together complex topics and making them readily understandable. And yet he never talked down to his audience. His leadership skills were highly effective, albeit in an understated manner. He became the Neurologist-in-Chief at Johns Hopkins from 1999-2006 and then the founding Director of the Brain Science Institute at Hopkins in 2007. He was also President of the American Neurological Association (2003$05)$ and the Peripheral Nerve Society (1997-99). He always was a devoted and generous mentor, attracting a steady stream of young trainees whose careers he fostered as well as recruiting high quality scientists to the Hopkins Department of Neurology. He had genuine interest in the work of others but was able to cast a critical eye over people's projects and to put things in a positive light. Jack would often sit patiently with enthusiastic postdoctoral fellows and students, listening as one after another presented their research and ideas, always providing invaluable feedback on how to refine their ideas and improve the experimental design - a true model of mentorship. Jack was perhaps at his peak when, at the teaching microscope with a group of residents and fellows, he would review clinical nerve biopsies while also teaching at the same time. Jack will be remembered by all who knew him as a thoughtful and engaging colleague. His wonderful sense of humor and his jolly laugh are enduring memories.

After a long battle with bladder cancer Jack Griffin left us too early, but he provided the neurology community with an enduring and rich legacy. 